\title{
EVALUACIÓN DE LA CALIDAD BACTERIOLÓGICA DE QUESOS FRESCOS EN CAJAMARCA
}

\section{EVALUATION OF THE BACTERIOLOGICAL QUALITY OF FRESH CHEESES FROM CAJAMARCA}

\author{
Víctor Vásquez A. ${ }^{1}$ José Gerardo Salhuana G. ${ }^{2}$, Luis A. Jiménez D. ${ }^{3}$ y Leidyn M. Abanto Ríos ${ }^{4}$
}

\begin{abstract}
Resumen
El queso fresco industrial proveniente de las principales empresas de la ciudad de Cajamarca, es ampliamente consumido por los pobladores de la ciudad; sin embargo, la población desconoce la calidad bacteriológica del mismo, representando un riesgo para su salud. Así mismo, no se cuenta con un banco de datos de toxiinfecciones alimentarias que se hayan presentado en la Región de Cajamarca. Siendo el objetivo de la investigación determinar la carga microbiana del queso fresco industrial, así como evaluar la calidad bacteriológica del mismo, mediante lo establecido por la Norma Sanitaria que constituye los Criterios Microbiológicos de Calidad Sanitaria e Inocuidad para los Alimentos y Bebidas de Consumo Humano. Para ello se tomó un total de 30 muestras de $0.5 \mathrm{~kg}$ cada una proveniente de 6 empresas productoras de queso fresco industrial (A, B, C, D, E y F). Se realizaron los análisis microbiológicos pertinentes para la determinación de mesófilos viables, coliformes, Escherichia coli, Salmonella spp. y Staphylococcus aureus. Se usó el diseño completamente al azar con 5 repeticiones. Al concluir el proceso de análisis se reportó los siguientes valores promedio de carga microbiana: mesófilos viables $1.06 \times 10^{5} \mathrm{UFC} / \mathrm{g}$, coliformes totales $6.32 \times 10^{3} \mathrm{NMP} / \mathrm{g}$, coliformes fecales $4.75 \times 10^{3} \mathrm{NMP} / \mathrm{g}$, muestras positivas para Escherichia coli $33.3 \%$, Staphylococcus aureus $4.02 \times 10^{3} \mathrm{UFC} / \mathrm{g}$ y ausencia de Salmonella spp. Estos resultados fueron comparados con la Norma Sanitaria que establece los Criterios Microbiológicos de Calidad Sanitaria e Inocuidad para los Alimentos y Bebidas de Consumo Humano" (R.M. N 591-2008MINSA). Concluyendo que los quesos de la empresa F presentan mejores condiciones microbianas. Palabras clave: queso, calidad bacteriológica, Escherichia coli, Staphylococus aureus, Salmonella spp.
\end{abstract}

\begin{abstract}
Iindustrial fresh cheese coming from the main companies of the city of Cajamarca, is widely consumed by the inhabitants of the city; however, the population does not know it's bacteriological quality, representing a health risk. Likewise, there is no data base of food intoxications presented in the Cajamarca Region. The objective of the research is to determine the microbial load of fresh industrial cheese, as well as to evaluate its bacteriological quality by means of what is established in the Sanitary Standard that constitutes the Microbiological Criteria of Sanitary Quality and Safety for Food and Beverage for Human Consumption. For this, a total of 30 samples of $0.5 \mathrm{~kg}$ each were taken from 6 companies producing industrial fresh cheese (A, B, C, D, E and F). The relevant microbiological analyzes were performed for the determination of viable mesophiles, coliforms, Escherichia coli, Salmonella spp. and Staphylococcus aureus. The design was completely randomized with 5 repetitions. At the conclusion of the analysis process, the following average valuesof microbial load were reported: viable mesophiles $1.06 \times 10^{5} \mathrm{CFU} / \mathrm{g}$, total coliforms $6.32 \times 10^{3}$ $\mathrm{MPN} / \mathrm{g}$, fecal coliforms $4.75 \times 10^{3} \mathrm{MPN} / \mathrm{g}$, positive samples for Escherichia coli $33.3 \%$, Staphylococcus aureus $4.02 \times 10^{3} \mathrm{CFU} / \mathrm{g}$ and absence of Salmonella spp. These results were compared with the Sanitary Standard that establishes the Microbiological Criteria of Sanitary Quality and Safety for Food and Beverage for Human Consumption "(R.M. N 591-2008-MINSA) concluding that the cheeses from company F present better microbial conditions.
\end{abstract}

Key words: cheese, bacteriological quality, Escherichia coli, Staphylococcus aureus, Salmonella spp. 


\section{Introducción.}

El queso es un alimento de amplio consumo a nivel mundial, cuyas características nutritivas, texturales y sensoriales difieren entre cada tipo. Se estiman más de 2000 variedades de queso entre madurados, semimadurados y frescos (Alais, 2003). No obstante, en nuestro país y la región Cajamarca predomina el consumo de quesos frescos, los mismos que forman parte de una enorme variedad de platillos que constituyen nuestro legado gastronómico (MINAGRI, 2009).

La práctica en torno a la elaboración del queso fresco ha sufrido importantes cambios, transformándola de un arte empírico a una tecnología industrial donde se han identificado diversos factores causantes de modificaciones en las propiedades del queso (microestructura, propiedades fisicoquímicas, texturales, y sensoriales), entre ellos, las condiciones del proceso, almacenamiento $\mathrm{y}$ las alteraciones provocadas por microorganismos, tales como: Escherichia coli, Salmonella spp., coliformes totales y fecales, Staphylococcus aureus, Listeria monocytogenes, entre otros; son considerados los principales causantes de intoxicación alimentaria (Otero, 1990)

Las intoxicaciones alimentarias, son enfermedades transmitidas por los alimentos y causadas ya sea por microorganismos patógenos o por las toxinas que estos producen (Rios et. al., 2012).

La R.M. N $^{\circ}$ 591-2008-MINSA (MINSA, 2008), dispone de criterios microbiológico que se deben cumplir para el subgrupo de quesos frescos, denotando valores mínimos y máximos que garanticen la inocuidad del alimento, haciendo referencia a la presencia de coliformes $\left(5 \times 10^{2}-10^{3}\right)$, Staphylococcus aureus $\left(10-10^{2}\right)$, Echerichia coli $(3-10)$, Listeria monocytogenes (ausencia/25g) y las Salmonela spp. (ausencia/25g). Por ello, se deben realizar controles bacteriológicos rigurosos y periódicos de este producto.

La presente investigación es de gran importancia ya que tiene como objetivo dar a conocer a la población la calidad bacteriológica del queso fresco que expenden las industrias más representativas de la ciudad de Cajamarca y determinar si no representan un riesgo para su salud.

\section{Metodología.}

Toma de muestras.

Se analizaron 05 muestras de 500 gramos de cada una de las empresa que formaron parte del estudio (A, B, C, D, E y F) en la ciudad de Cajamarca, verificándose que provenían de la misma fecha de producción; la toma de muestras se realizó del almacén de producto terminado dos horas antes de su análisis y transportadas a las instalaciones del laboratorio de microbiología de la Universidad Nacional de Cajamarca, manteniéndose en coolers en refrigeración con ice pack hasta su análisis.
Análisis microbiológico.

Preparación de la muestra.

La preparación de las muestras se realizó según la metodología de la Organización de las Naciones Unidas para la Agricultura y la Alimentación (FAOOMS, 2008) y la Comisión Internacional para las Especificaciones Microbiológicas de los Alimentos (ICMSF, 2006).

Recuento de mesófilos viable.

Se pesaron 25 gramos de muestra de queso fresco industrial y se homogenizó con $225 \mathrm{ml}$ de agua peptonada estéril (APE) 0.1. Se realizaron diluciones decimales hasta $10^{-3}$ en APE 0.1 y a partir de cada una se inocularon $0.1 \mathrm{ml}$ por vaciado o agotamiento en placa por duplicado en recuento por placa de agar (PCA) luego se incubaron a $35^{\circ} \mathrm{C}$ por $48 \mathrm{~h}$. A partir del número de colonias obtenidas, se calculó el número de microorganismos por gramo de muestra.

Determinación de coliformes y Escherichia coli.

La determinación del número más probable (NMP) de bacterias coliformes se hizo mediante la técnica de los tubos múltiples, en la cual volúmenes decrecientes de la muestra (diluciones decimales consecutivas) fueron inoculadas en medio de cultivo adecuado.

La combinación de los resultados positivos y negativos fue usada en la determinación del NMP.

Prueba presuntiva.

Se pesaron 25 gramos de muestra de queso fresco industrial y se homogenizó en $225 \mathrm{ml}$ de APE 0.1. Se realizaron diluciones decimales hasta $10^{-3}$ en APE 0.1 y a partir de cada dilución se inoculó $1 \mathrm{ml}$ en tubos conteniendo caldo lauril sulfato que fueron incubados a $35^{\circ} \mathrm{C} \pm 0.5^{\circ} \mathrm{C}$ durante $24-48$ horas en baño maría. En esta prueba presuntiva, la actividad metabólica de las bacterias es estimulada vigorosamente y ocurre una selección inicial de organismos que fermentan la lactosa con producción de gas. La formación de gas a $35^{\circ} \mathrm{C} \pm 0.5^{\circ} \mathrm{C}$ dentro las $24-48$ horas, constituye una prueba presuntiva positiva para la presencia de bacterias del grupo coliformes (Ratto, 1982).

Prueba confirmativa para coliformes totales.

Consistió en transferir 2 asadas de cada tubo positivo de la prueba presuntiva a tubos conteniendo caldo lactosado verde brillante bilis $2 \%$ con campana de Durham, se agitó suavemente para su homogenización y fueron incubados durante 24-48 horas a $35^{\circ} \mathrm{C} \pm 0.5^{\circ} \mathrm{C}$ en baño maría. Esta prueba reduce la posibilidad de resultados falsos gas-positivos que pueden ocurrir por la actividad metabólica de los organismos formadores de esporas o por la producción sinérgica de gas debido a que algunas cepas de bacterias no pueden, individualmente, producirlo a partir de la fermentación de la lactosa.

El caldo lactosado verde brillante bilis contiene agentes inhibidores que suprimen el desarrollo de todos los microorganismos no coliformes. La producción de gas a $35^{\circ} \mathrm{C}$ después de las $24-48$ horas constituye una prueba confirmativa positiva de coliformes totales, 
después del periodo de incubación se consultó la tabla del NMP para conocer el número más probable de coliformes totales/g de muestra (Doyle et al., 1997).

Prueba confirmativa para coliformes fecales.

Consistió en transferir 2 asadas de cada tubo positivo de la prueba presuntiva, a tubos con caldo $E$. coli, se agitaron suavemente para su homogenización, luego se incubó a $45^{\circ} \mathrm{C} \pm 0.5^{\circ} \mathrm{C}$ por $24-48$ horas en baño maría, se registró como positivos todos los tubos donde se observó producción de gas después del periodo de incubación, posteriormente se consultó en la tabla del NMP para conocer el número más probable de coliformes fecales/g muestra.

Prueba confirmativa para $\underline{\text { E. coli. }}$.

Consistió en transferir 2 asadas de los tubos positivos de caldo $E$. coli a tubos con caldo triptona, luego se incubó a $35{ }^{\circ} \mathrm{C} \pm 0.5^{\circ} \mathrm{C}$ durante $24 \pm 2$ horas, posteriormente se confirmó con $0.5 \mathrm{ml}$ de reactivo de Kovacs. Se consideró positivo si la coloración fue rojo y negativo si fue amarillo. Otra prueba consistió en tomar 2 asadas de los tubos positivos de caldo $E$. coli y sembrados por estría en agar con eosina y azul de metileno, luego fueron incubadas a $35{ }^{\circ} \mathrm{C} \pm 0.5^{\circ} \mathrm{C}$ durante $24 \pm 2$ horas. Se consideraron positivas las colonias negras típicas nucleadas con o sin brillo metálico

\section{Recuento de Staphylococcus aureus.}

Se pesaron 25 gramos de muestra de queso fresco industrial y se homogenizó en $225 \mathrm{ml}$ de APE $0.1 \%$. Se realizaron diluciones decimales hasta $10^{-3}$ en APE $0.1 \%$ y a partir de cada una se inocularon $0.1 \mathrm{ml}$ en placas con agar Baird Parker por duplicado y se incubaron a $37^{\circ} \mathrm{C}$ por 48 horas. Se consideraron sospechosas las colonias que presentaron una coloración negra o gris con zonas parcialmente opacas.

Para la prueba confirmativa se seleccionaron, dos colonias típicas; con este fin, se investigó la capacidad de la cepa en estudio para producir Coagulasa. La coagulasa es un enzima capaz de desnaturalizar la fibrina del plasma. La mayoría de las cepas de Staphylococcus aureus patógenas (enterotoxigénicas) producen esta enzima (Ratto, 1982).

Las colonias típicas seleccionadas se sembraron en caldo infusión cerebro-corazón, BHI (Brain Heart Infusion) contenido en tubos. Luego se incubaron a 37 ${ }^{\circ} \mathrm{C}$ durante 18-24 horas.

Posteriormente se realizó la prueba de la coagulasa que consistió en transferir en un tubo estéril $0.5 \mathrm{ml} \mathrm{de}$ caldo cerebro corazón del cultivo obtenido más $0.5 \mathrm{ml}$ de plasma de conejo, luego se mezclaron suavemente e incubaron a $37^{\circ} \mathrm{C} / 24 \mathrm{~h}$. La reacción es positiva cuando el coágulo formado es firme. La reacción es negativa cuando no se coagula el plasma (Doyle et al., 1997).

Determinación de Salmonella spp.

Se pesaron 25 gramos de cada muestra y se homogenizaron en $225 \mathrm{ml}$ de caldo lactosado simple el cual se incubó por $24 \mathrm{~h}$ a $37^{\circ} \mathrm{C}$. Luego se transfirió $1 \mathrm{ml}$ de cultivo de preenriquecimiento en caldo selenito cistina y $1 \mathrm{ml}$ en caldo tetrationato para el enriquecimiento selectivo, ambos tubos se incubaron a $37^{\circ} \mathrm{C} / 24$ horas. A partir de estos se sembró por estría en agar Salmonella - Shigella y en agar bismuto sulfito e incubó ambas en posición invertida a $37^{\circ} \mathrm{C} / 24$ horas.

Agar Salmonella-Shigella (S.S): Colonias transparentes con centro negro.

Agar bismuto sulfito (B.S): Colonias negras brillantes.

Análisis estadístico.

Los resultados de los análisis microbiológicos realizados se transformaron a $\log 10$ UFC (Unidades Formadoras de Colonias)/g o ml, se analizó la calidad del queso fresco.

Se utilizó un diseño experimental completamente al azar (DCA) mediante el siguiente modelo general lineal:

$$
y_{i j}=\mu+\tau_{i}+\varepsilon_{i j}\left\{\begin{array}{l}
i=1,2, \ldots, 6 \\
j=1,2, \ldots, 5
\end{array}\right.
$$

Donde:

$\mathrm{Y}_{\mathrm{ij}}=$ variable respuesta

$\mu=$ media general

$\tau \mathrm{i}=$ número de tratamentos

$\varepsilon i j=$ es el efecto verdadero del i-ésimo tratamiento, sujeto a la j-ésima unidad experimental (error experimental).

Se realizó un análisis de varianza (ANOVA) a un nivel de significancia $(\mathrm{P}<0.05)$ utilizando el comando del modelo general lineal del software estadístico SAS v9.4. Cuando se observaron diferencias significativas $(\mathrm{p}<0.05)$ se aplicó la prueba de rango múltiple Duncan (Vásquez, 2014).

\section{Resultados.}

El análisis de los resultados se determinó a partir de 30 muestras al azar de queso fresco procedentes de seis empresas industriales de Cajamarca (A, B, C, D, E y F). Variables microbiológicas evaluadas.

\section{Mesófilos viables.}

Se detectaron mesófilos en las seis empresas. El análisis estadístico mostró significación estadística ( $\mathrm{P}$ $>0.05$ ) para la fuente de variación empresas. La Figura 1 revela que los promedios más altos de mesófilos viables se encontraron en la empresa A con $16 \times 10^{4}$ $\mathrm{UFC} / \mathrm{g}$, superando estadísticamente a todas las empresas restantes. Destacan las empresas E y F en donde se detectan los valores más bajos de mesófilos viables con $75 \times 10^{3} \quad \mathrm{UFC} / \mathrm{g}$ y $34 \times 10^{3} \quad \mathrm{UFC} / \mathrm{g}$, respectivamente. Siendo estas empresas las únicas que cumplen con lo establecido por la ICMSF (2006) por estar debajo del límite máximo permisible para mesófilos viables que es de $10^{5} \mathrm{UFC} / \mathrm{g}$.

Staphylococcus aureus.

Se encontró S. aureus en $25(83 \%)$ de las 30 muestras estudiadas (Figura 2), las diferencias 


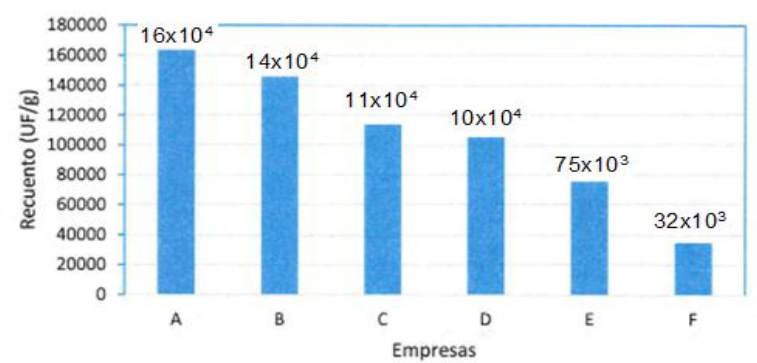

Figura 1. Recuento promedio para mesófilos viables en muestras de queso fresco industrial.

altamente significativas para las empresas demuestran una respuesta desigual. Usando la prueba de comparación de medias Duncan $(\alpha=0.05)$, la empresa A supera estadísticamente a los promedios de las cinco empresas restantes, con el valor de $S$. aureus $\left(55 \times 10^{2}\right.$ $\mathrm{UFC} / \mathrm{g})$. No hay diferencias estadísticas entre los promedios encontrados en las empresas D y E con $32 \times 10^{2} \quad \mathrm{UFC} / \mathrm{g}$ y $29 \times 10^{2} \mathrm{UFC} / \mathrm{g}$ respectivamente. Ocupa el último lugar la empresa $\mathrm{F}$, en donde no se presentó crecimiento de agente microbiano (ausencia/25g).

Coliformes totales.

Los resultados sobre el contenido de las bacterias coliformes totales en las 30 muestras analizadas indican que hubo variación significativa entre las seis empresas. La significación estadística al $1 \%$ de probabilidades indica que hay diferencias reales entre los promedios de las bacterias coliformes entre las empresas. La Figura 3 presenta las grandes diferencias con respecto a la presencia de coliformes.

En la Figura 3 se aprecia que los quesos provenientes de las empresas $\mathrm{E}$ y $\mathrm{F}$ presentan promedios menores a $10^{3} \mathrm{NMP} / \mathrm{g}$ para coliformes totales. En la empresa A se halló $22 \times 10^{3} \mathrm{NMP} / \mathrm{g}$ superando estadísticamente a las cinco empresas restantes. El contenido promedio de coliformes totales en las empresas B, C y D, variaron de $29 \times 10^{2} \mathrm{NMP} / \mathrm{g}$, $27 \times 10^{2} \mathrm{NMP} / \mathrm{g}$ y $25 \times 10^{2} \mathrm{NMP} / \mathrm{g}$ respectivamente. Entre dichas empresas no hubo diferencias estadísticas significativas. Así mismo, no hubo diferencias estadísticas entre los promedios de coliformes totales entre las empres $\mathrm{E}$ y $\mathrm{F}$ cuyo promedios fueron $85 \times 10$ $\mathrm{NMP} / \mathrm{g}$ y $66 \times 10 \mathrm{NMP} / \mathrm{g}$ respectivamente.

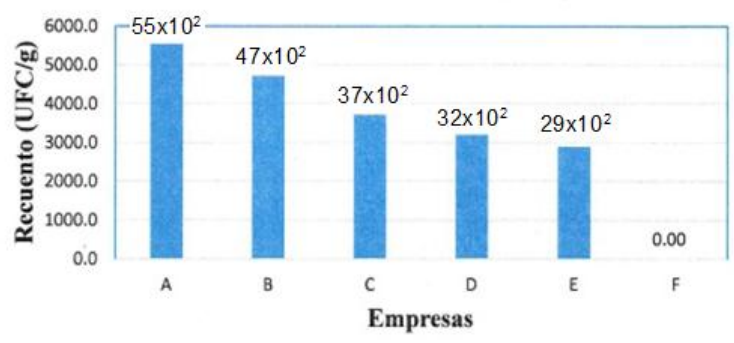

Figura 2. Recuento promedio de S. aureus de acuerdo al contenido por gramo de muestra en las seis empresas.

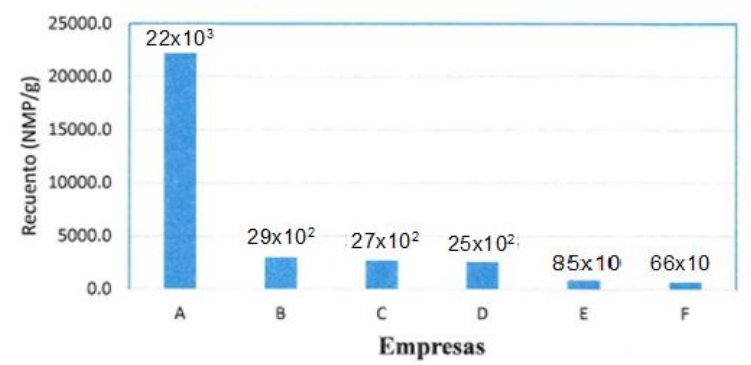

Figura 3. Promedio de coliformes totales según el $\mathrm{NMP} / \mathrm{g}$ en las seis empresas.

Coliformes fecales.

Al realizar el análisis estadístico del recuento de coliformes fecales, se encontró significación estadística $(\mathrm{P}>0.01)$ el cual sugiere que hay diferencias reales entre los promedios provenientes de las diferentes empresas.

La prueba de comparación de medias (Figura 4) indica que en la empresa A se halló $21 \times 10^{3} \mathrm{NMP} / \mathrm{g}$, valor promedio que estadísticamente supera a los promedios alcanzados en las cinco empresas restantes. No hay diferencias estadísticamente significativas entre los promedios de coliformes fecales entre las empresas $\mathrm{B}, \mathrm{C}, \mathrm{D}, \mathrm{E}$ y $\mathrm{F}$ cuyos valores promedios fueron de $24 \times 10^{2} \mathrm{NMP} / \mathrm{g}, 22 \times 10^{2} \mathrm{NMP} / \mathrm{g}, 21 \times 10^{2} \mathrm{NMP} / \mathrm{g}, 54 \times 10$ $\mathrm{NMP} / \mathrm{g}$ y $32 \times 10 \mathrm{NMP} / \mathrm{g}$ respectivamente.

Escherichia coli.

La Tabla 1 presenta el total de muestras analizadas, y el número de muestras que dieron un resultado positivo, además se estima el porcentaje de muestras positivas de E. coli para cada una de las empresas productoras de queso fresco industrial.

Se aprecia que la empresa $\mathrm{F}$ no presenta muestras positivas. En cambio en las empresas restantes $(\mathrm{C}, \mathrm{A}$, $\mathrm{D}, \mathrm{B}$ y E) se han encontrado porcentajes que oscilan entre $20 \%$ al $100 \%$. Estos resultados positivos para Escherichia coli confirman la evidente contaminación de origen fecal por la falta de higiene durante el periodo de elaboración o manipulación del producto.

Salmonella spp.

En la Tabla 2 se presenta la determinación de la Salmonella spp.

Se observa en la Tabla 2 que, el $100 \%$ de las empresas productoras de queso fresco industrial no se reporta presencia de Salmonella spp.

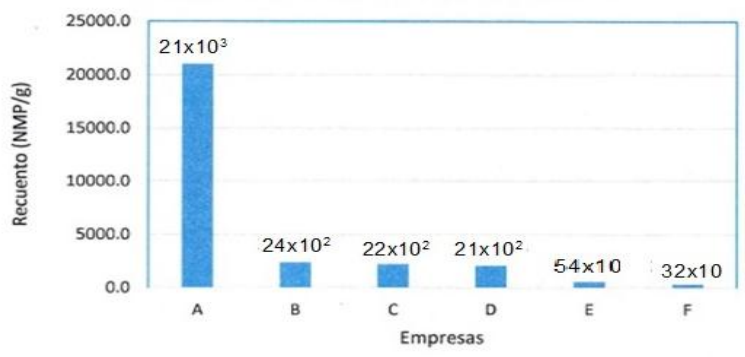

Figura 4. Coliformes fecales promedio por empresa. 
Tabla 1. Muestras positivas de Escherichia coli en el análisis de queso fresco industrial.

\begin{tabular}{cccc}
\hline Empresa & $\begin{array}{c}\text { Cantidad } \\
\text { de } \\
\text { muestras } \\
\text { analizadas }\end{array}$ & $\begin{array}{c}\text { Muestras } \\
\text { positivas }\end{array}$ & $\begin{array}{c}\text { E. coli } \\
(\%)\end{array}$ \\
\hline C & 5 & 1 & $20 \%$ \\
A & 5 & 5 & $100 \%$ \\
D & 5 & 1 & $20 \%$ \\
B & 5 & 2 & $40 \%$ \\
E & 5 & 1 & $20 \%$ \\
F & 5 & 0 & $0 \%$ \\
\hline
\end{tabular}

En la Figura 5 se observa que en el 100\% (30 muestras) de las empresas productoras de queso fresco industrial se reportó ausencia de Salmonella, spp. lo cual es favorable, ya que cumple con lo establecido por la R.M. 591-2008-MINSA (ausencia/ 25g de Salmonella spp.).

Hubo diferencias reales respecto a mesófilos viables y Staphylococcus aureus, sin embargo, no existen diferencias entre las medias de las empresas $\mathrm{D}$, $\mathrm{C}$ y $\mathrm{B}$ respecto a coliformes totales y entre $\mathrm{E}, \mathrm{D}, \mathrm{B}, \mathrm{C}$ y $\mathrm{F}$ respecto a coliformes fecales y entre D y E respecto a Staphylococcus aureus.

\section{Discusión.}

De las 30 muestras de queso fresco tomadas de 5 empresas de Cajamarca, observamos que hay un alto porcentaje de muestras contaminadas con microorganismos que nos expresan condiciones higiénicas deficientes en su elaboración, transporte o comercialización en relación a lo dispuesto en la R.M. $\mathrm{N}^{\circ}$ 591-2008-MINSA (Norma sanitaria que establece los criterios microbiológicos de calidad sanitaria e inocuidad para los alimentos y bebidas de consumo humano), NTP (Norma Técnica Peruana) 202.193:2010 (Leche y productos lácteos: queso, identificación, clasificación y requisitos), NTP 202,195 (Leche y Productos Lácteos. Queso fresco.), NTP 202.087 (Leche y Productos Lácteos Queso Fresco 2da. Edición. 2010).

Mesófilos viables.

Los recuentos promedios de mesófilos viables encontrados en las empresas A, B, C y D han superado

Tabla 2. Determinación de la Salmonella spp. en muestras de queso obtenidas de empresas de Cajamarca.

\begin{tabular}{ccc}
\hline Empresas & $\begin{array}{c}\text { Cantidad } \\
\text { de } \\
\text { muestras } \\
\text { anlizadas }\end{array}$ & $\begin{array}{c}\text { Salmonella } \text { sp. } \\
\text { (UFC/g) }\end{array}$ \\
\hline C & 5 & Ausente \\
A & 5 & Ausente \\
D & 5 & Ausente \\
B & 5 & Ausente \\
E & 5 & Ausente \\
F & 5 & Ausente \\
\hline
\end{tabular}

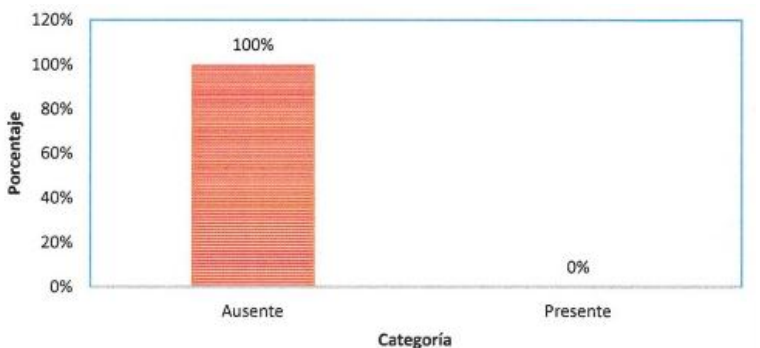

Figura 5. Recuento de Salmonella spp. En muestras de queso fresco industrial.

el límite establecido por ICMSF (2006) que es $10^{5}$ UFC/g. Silva et al, (2010) tuvieron resultados similares con carga bacteriana elevada de los quesos muestreados. La elevada carga microbiana en las muestras de queso industrial refleja deficiencias higiénicas en la manipulación del queso fresco, lo cual representa un riesgo para la salud del consumidor. Peláez (1985) manifiesta que recuentos altos de la flora aerobia mesófila, puede deberse a una contaminación excesiva de la materia prima y a una elevada proporción de microorganismos termorresistentes, o bien a una mala pasteurización o una recontaminación posterior al tratamiento térmico.

Staphylococcus aureus.

Nuestros resultados concuerdan con los reportes de Chávez (2006) quien a través de un estudio sobre las condiciones microbiológicas y fisicoquímicas de queso fresco reporta recuentos de $10^{2} \mathrm{UFC} / \mathrm{g}$ hasta $16 \times 10^{4}$ UFC/g de Staphylococcus aureus indicando que es una evidencia de la deficiente condición higiénico-sanitaria durante la elaboración del queso. Los resultados obtenidos de $40 \times 10^{2} \mathrm{UFC} / \mathrm{g}$ en el presente experimento expresa valores que sobrepasa los límites establecidos por la NTP 202.087, esto podría deberse a una deficiente aplicación de buenas prácticas de manufactura en el procesamiento debido a que son bacterias presentes en el cuerpo de animales y el hombre, principalmente en la piel, las fosas nasales, faringe, boca y manos lo que convierte a los manipuladores en potenciales contaminantes. Escobar (1990) señala que la piel de las ubres de las vacas y el suelo también contienen gran cantidad de estos microorganismos que de manera directa o indirecta pueden llegar a contaminar la leche.

Coliformes totales.

Los recuentos de coliformes totales encontrados en las empresas E ( $85 \times 10 \mathrm{NMP} / \mathrm{g})$ y F $(65 \times 10 \mathrm{NMP} / \mathrm{g})$ son menores a $10^{3} \mathrm{NMP} / \mathrm{g}$. Se encuentran dentro del rango establecido por la NTP: R.M. 591-2008-MINSA (MINSA, 2008). Los promedios obtenidos en las empresas A, B, C y D no cumplen con lo establecido por la NTP, debido a que se obtuvieron recuentos de hasta $10^{4} \mathrm{NMP} / \mathrm{g}$. Maldonado \& Llanca (2008) y Fuentes (2003), indican que el elevado recuento de coliformes totales, está relacionado con la materia prima, el lugar donde se realiza la extracción y las 
condiciones higiénicas donde se lleva a cabo, el tiempo de almacenamiento de la leche antes de la elaboración del queso. Así mismo, tiene que ver las condiciones de transporte, almacenamiento (temperatura ambiente) y una excesiva manipulación a la que se ven sometidos hasta la venta. Teniendo en cuenta lo antes mencionado es imposible eliminarlos en su totalidad a los coliformes totales.

Coliformes fecales.

Los resultados muestra que las únicas empresas que cumplen con lo establecido por la norma son $\mathrm{E}$ y $\mathrm{F}$, debido a que muestran valores menores a $10^{3}$. Las empresas A, B, C y D presentan recuentos de coliformes fecales que superan el límite establecido por la NTP (MINSA, 2008), lo que podría deberse a una probable contaminación de origen fecal. La presencia de coliformes fecales en las cuatro empresa citadas coincide con lo planteado por Stanley (1998), Sánchez (2004), Bachmann \& Spahr (1995) y Cristobal \& Maurtua (2003) quienes mencionan que la contaminación por bacterias (coliformes fecales) es debido principalmente a la falta de pasteurización de la leche y a las condiciones poco higiénicas en que se lleva a cabo el proceso de producción del queso fresco. Escherichia coli.

La ausencia de la bacteria $E$. coli en la empresa F indica que cumple con lo establecido por la NTP (MINSA, 2008). Las empresas C, A, D, B y E cuyos resultados son positivos reflejan la falta de higiene durante la elaboración o manipulación del producto. Márquez \& García (2007) reportan valores similares a los nuestros. Rodríguez et al. (2015) mencionan que la presencia de esta bacteria es un importante indicador de contaminación fecal que advierte de la posible presencia de otros patógenos en las muestras de queso comercializadas; la alta prevalencia de $E$. coli en quesos implica un riesgo potencial de enfermedades transmitidas por alimentos si los productos se consumen frescos. Silva et al. (2006) describen que algunos quesos frescos de Brasil presentan conteos muy elevados de $E$. coli siendo estos no aptos para consumo humano, ya que la presencia de E. coli indica una contaminación fecal.

Salmonella spp.

En el presente estudio no se encontró Salmonella spp. en el queso fresco, pero existen factores como el $\mathrm{pH}$ ácido, baja disponibilidad de azúcares que afectan su desarrollo además de la competencia con otros microorganismos que posean una tasa de duplicación mayor, así como tensiones de oxígeno bajas en el queso fresco puede enmascarar la presencia de este microrganismo (Fuentes, 2003).

Santa Cruz et. al. (2006) reportan que la elaboración de quesos frescos de manera industrial y su consumo en la ciudad de Cajamarca se han visto involucradas por diversos brotes de enfermedades alimentarias infecto contagiosas como lo es la salmonelosis. Al respecto Alerte et al. (2012), indica que el consumo de quesos contaminados, ocasionados por la falta de control durante el proceso de elaboración, o la utilización de leche cruda contaminada, conduce a peligros microbianos.

\section{Conclusiones.}

La empresa $F$ presenta mejores condiciones microbiológicas para la elaboración de queso fresco, de acuerdo a la R.M. 591-2008-MINSA.

Las empresas D, B, A, E y C presentan una elevada contaminación por bacterias indicadoras de contaminación fecal (coliformes y E. coli), para el lote de queso fresco analizado superando los límites permisibles por la norma.

La carga microbiana promedio de todas las muestras de queso fresco industrial ha superado los límites establecidos por la NTP.

\section{Recomendaciones.}

Se recomienda hacer un estudio de cada etapa en la elaboración de queso fresco, para identificar en cuál de éstas se produce mayor contaminación para que puedan controlar y minimizar la carga microbiana del producto terminado.

\section{Literatura citada.}

Alais Ch. 2003. Ciencia de la Leche. Principio de Técnica Lechera. Cuarta edición. Editorial Reverte. S.A. Barcelona, España.

Rios C., Paris E., Bettini M., \& Repetto G. 2012. Manejo clínico de las intoxicaciones alimentarias. Ediciones Díaz de Santos. Argentina.

Alerte V., Cortés S., Díaz J., Vollaire J., Espinoza M.E., Solari V., Cerda J. \& Torres M. 2012. Brotes de enfermedades transmitidas por alimentos y agua en la Región Metropolitana, Chile (2005-2010). Revista Chilena de Infectologia, Santiago, v. 29, n. 1, p. 26-31,. http://dx.doi.org/10.4067/S0716-10182012000100004. PMid:22552507.

Bachmann H. \& Spahr U. 1995. The fate of potentially pathogenic bacteria in Swiss hard and semihard cheese from raw milk. Journal of Dairy Science, 78: pp 476 483.

Cristobal R.L \& Maurtua D.J. 2003. Evaluación bacteriológica de quesos frescos artesanales comercializados en Lima, Perú, y la supuesta acción bactericida de Lactobacillus spp. Revista Panamericana de Salud Pública.

Chávez E. 2006. Diagnóstico de las condiciones microbiológicas y fisicoquímicas del queso costeño producido en el Municipio de Sincé - Sucre- Colombia. Tesis Para optar el grado de Ingeniero Agroindustrial.

Doyle M., Beuchat L. \& Montville T. 1997. Microbiologia de los alimentos: fundamentos y fronteras. Editorial acribia. Zaragoza-España. p.581-597.

Escobar E. 1990. Fabricación de productos lácteos y calidad microbiológica. Editorial Acribia. Zaragoza- España.

FAO-OMS. 2008. Organización de las Naciones Unidas para la Agricultura y la Alimentación-Organización Mundial de la Salud. Cultivos lácteos y productos lácteos fermentados. Manual correspondiente al módulo III. 
Productos fermentados y queso. Equipo de fomento y capacitación en la lechería de FAO para América Latina.

Fuentes L. 2003. Estudio de parámetros Microbiológicos que afectan la calidad del Queso tipo Gouda. Valparaiso Chile.

ICMSF. 2006. Guía de Interpretación de Resultados Microbiológicos de Alimentos. Principios y aplicaciones específicas. University of Toronto Press.

ICMSF. 1988. Comisión Internacional para las Especificaciones Microbiológicas de los Alimentos.

Maldonado R. \& Llanca L. 2008. Estudio de la calidad del queso fresco comercializado en el municipio Girardot, estado Aragua, Venezuela. Rev. Científica FCV LUZ. P.431-436.

Márquez J.G. \& García R.C.E. 2007. Microflora patógena del queso blanco "Telita" elaborado en cuatro estados de Venezuela. Anales Venezolanos de Nutrición, v. 20, n. 1, p. $17-21$.

MINSA. 2008. R.M. N 591-2008-MINSA: Norma Sanitaria que establece los Criterios Microbiológicos de Calidad Sanitaria e Inocuidad para los Alimentos y Bebidas de Consumo Humano (Criterio I. 1.8).

MINAGRI. 2009. Ministerio De Agricultura y Riego. Producción De Leche Fresca En El Perú. Disponible en http://www.minagri.gob.pe/portal/notas-de50prensa/2009/2206-produccion-de-leche-fresca-en-elperu-crece-a-una-tasa-anual-de-5.

Otero A. 1990. Microorganismos patógenos en el queso. Industrias Lácteas Españolas. Editoril Acribia, S.A. Zaragoza, España.
Peláez C. 1985. Control de calidad microbiológico de productos lácteos terminados. Revista Española de Lechería. P. 21-29.

Ratto M. 1982. Control microbiológico de leche y productos lácteos. Métodos recomendados. Lima, Perú.

Rodríguez J.E., Borras L.M., Pulido M.O. \& García D.J. 2015. Calidad microbiológica en quesos frescos artesanales distribuidos en plazas de mercado de Tunja, Colombia. Universidad Pedagógica y Tecnológica de Colombia. Tunja. Colombia. Vol.53, Num. 3.

Santa Cruz V., Sánchez M. \& Pezo S. 2006. Análisis de la Cadena Productiva de Lácteos Cajamarca. Informe final. CODELAC

Sánchez C. 2004. La utilización de leche cruda versus pasteurizada en la elaboración de Quesos. III.

Silva M.P., Cavallid D.R. \& Olivera T.C.R.M. 2006. Avaliação do padrão coliformes a $45^{\circ} \mathrm{C}$ e comparação da eficiência das técnicas dos tubos múltiplos e Petrifilm ec na detecção de coliformes totais e Escherichia coli em alimentos. Ciência e Tecnologia de Alimentos, Campinas, v. 26, n. 2, p. 352-359. http://dx.doi.org/10.1590/S0101-20612006000200018.

Silva G.S.E., Reséndiz M.R., Hernández Z.J.S., Pérez A.R. \& Pérez B.J. 2010. El Queso fresco Artesanal de vaca: Calidad Bacteriológica. Memorias, XI Simposio Iberoamericano sobre Conservación y Utilización de Recursos Zoogenéticos. 17, 18 y 19 Noviembre/2010. Joao Pessoa-Paraiba Brazil.

Stanley G. 1998. Microbiología de los productos lácteos fermentados. 2 ed. Editorial Aceibia. Zaragoza, España.

Vásquez A.V. 2014. Diseños experimentales con SAS. Edita CONCYTEC-FONDECYT, Lima-Perú.

\footnotetext{
${ }^{1}$ Departamento de Agronomía, Facultad de Ciencias Agrarias, Universidad Nacional de Cajamarca. Av. Atahualpa $\mathrm{N}^{\circ} 1050$. vvarce@ hotmail.com.

${ }^{2}$ Departamento de Agronomía, Facultad de Ciencias Agrarias, Universidad Nacional de Cajamarca. Av. Atahualpa $\mathrm{N}^{\circ}$ 1050. salhuana1@ hotmail.com.

${ }^{3}$ Facultad de Economía y Planificación, Universidad Nacional Agraria La Molina. Av. La Molina s/n, Lima 12, Perú.

${ }^{4}$ Departamento de Agronomía, Facultad de Ciencias Agrarias, Universidad Nacional de Cajamarca. Av. Atahualpa $\mathrm{N}^{\circ}$ 1050. marilyne_90@ hotmail.com.
} 